\title{
IDENTIFIKASI TINGKAH ALPHA MALE MONYET HITAM (Macaca nigra) DI CAGAR ALAM TANGKOKO
}

\author{
Ryan G. H. Mondoringin*, Rita S.H.Wungow, Jantje Paath, Joice J.I. Rompas
}

Fakultas Peternakan Universitas Sam Ratulangi Manado, 95115

\begin{abstract}
ABSTRAK
Penelitian ini bertujuan untuk mendapatkan data spesifik terbaru mengenai tingkah-laku Alpha male/jantan dominan dalam kelompok Rambo 1 di Cagar alam Tangkoko. Materi yang digunakan 1 Monyet Hitam Jantan Dominan (Alpha Male) pada kelompok Rambo 1 yang berada di Cagar Alam Tangkoko Batuangus Bitung Sulawesi Utara. Data yang diperoleh dianalisis dan disajikan secara deskriptif dalam bentuk grafik atau histogram.

Berdasarkan hasil dan pembahasan, maka dapat ditarik kesimpulan sebagai berikut: (1) Aktifitas yang paling lama dilakukan Alpha Male/Jantan Dominan pada pagi hari adalah locomotion dan foraging dan agonistic. Sedangkan pada siang hari adalah: foraging, locomotion, grooming, dan inactive. (2) Aktifitas yang paling sedikit dilakukan baik pada pagi hari maupun siang hari adalah aktivitas kawin (coitus). (3) Tingkah laku Jantan Dominan Alpha Male adalah berbeda dengan monyet hitam lainya dalam satu kelompok .
\end{abstract}

Kata kunci : Alpha male (Macaca nigra), identifikasi tingkah

\section{ABSTRACT \\ IDENTIFICATION OF ALPHA MALE BLACK MONKEY (Macaca nigra) BEHAVIOR IN THE NATURE RESERVE TANGKOKO. This study aims to get the latest specific data regarding behavior Alpha}

*Korespondensi (corresponding author):

Email: ryanmondoringin26@gmail.com male / Rambo dominant male in the group 1 in the nature reserve Tangkoko. Materials used 1 Monkey Black Male Dominant (Alpha Male) in group 1 residing Rambo in Tangkoko Nature Reserve Batuangus Bitung, North Sulawesi. The data obtained are analyzed and presented descriptively in the form of graphs or histograms. Based on the results and discussion, it can be concluded as follows: (1) The most long-standing activity Alpha Male / Male Dominance in the morning is locomotion and foraging and agonistic. During the day are: foraging, locomotion, grooming, and inactive. (2) Activities are at least done either in the morning or during the day is the mating activity (coitus). (3) Behaviour Males Dominant Alpha Male is different from other black monkeys in one group

Keywords: Alpha Male (Macaca nigra), identification of behavior

\section{PENDAHULUAN}

Monyet hitam hidup berkelompok dengan ukuran kelompok saat ini sekitar \pm 60-82 ekor baik jantan maupun betina. Monyet Hitam memiliki pemimpin dalam tiap kelompok yang disebut jantan dominan (alpha male). Jantan dominan (alpha male) memiliki tubuh dan 
suara yang khas. Penentuan jantan dominan Monyet Hitam dapat dilihat dengan memperhatikan Monyet Hitam yang selalu diikuti dan ditakuti oleh Monyet Hitam lain dalam grupnya dan selalu diberikan perlakuan yang special baik betina dewasa, jantan dewasa lain maupun juvenille.

Keunikan yang dimiliki jantan dominan (alpha male) menambah daya tarik tersendiri yang dimiliki monyet hitam. Tingkah laku/interaksi jantan dominan dalam kelompok sedikit berbeda dengan tingkah laku monyet lainnya. Peranan alpha male dalam satu kelompok monyet hitam sangatlah penting karena berperan sebagai pemimpin dan pelindung kelompoknya serta menjaga betina yang ada dalam kelompoknya untuk memenuhi kebutuhan reproduksi.

Informasi tentang tingkah laku jantan dominan masih sangat kurang karena itu pengamatan tingkah-laku jantan dominan penting dilakukan untuk mendapatkan data spesifik mengenai tingkah-laku jantan dominan yang sudah pasti berbeda dengan monyet hitam lainya dalam satu kelompok, selain itu informasi ini dapat menunjang usaha pelestarian dan peningkatan populasi Macaca nigra.

\section{MATERI DAN METODE PENELITIAN}

Penelitian ini dilakukan di Cagar Alam Tangkoko Bitung Sulawesi Utara dan waktu penelitian 2 bulan dimulai bulan November 2014 sampai bulan Januari 2015. Penelitian ini menggunakan 1 monyet hitam jantan dominan (alpha male) pada kelompok rambo 1 yang berada di Cagar Alam Tangkoko Batu Angus Bitung Sulawesi Utara.

Penelitian ini menggunakan metode observasi, yaitu pengamatan secara langsung di lokasi yang dijadikan tempat penelitian. Data yang diperoleh dianalisis dan disajikan secara deskriptif dan dalam bentuk grafik atau histogram yang diuraikan sebagai berikut:

1. Deskriptif yaitu penguraian dan penjelasan mengenai gambarangambaran umum dari hasil pengamatan secara langsung.

2. Grafik/histogram yaitu untuk memberikan gambaran dari setiap variabel yang diamati dalam penelitian ini.

\section{HASIL DAN PEMBAHASAN}

Pengamatan tingkah-laku jantan dominan penting dilakukan untuk mendapatkan data spesifik mengenai 
jantan dominan yang sudah pasti berbeda dengan Monyet Hitam (Macaca nigra) lainya dalam satu kelompok, selain itu informasi ini dapat menunjang usaha pelestarian dan populasi Monyet Hitam (Macaca nigra) dalam upaya peningkatan populasi satwa tersebut.

Jantan dominan (alpha male) merupakan pemimpin yang ada dalam kelompok. Pemimpin ini memiliki tubuh dan suara yang khas. Pemimpin kelompok ini disebut jantan dominan/alpha male. Dalam keseharian pemimpin ini mudah dikenali dimana Monyet Hitam (Macaca nigra) ini selalu diikuti dan ditakuti oleh Monyet Hitam (Macaca nigra) lain dalam groupnya dan selalu diberikan perilku yang spesial baik betina dewasa, jantan dewasa lain maupun juvennile, dengan demikian satu jantan dominan/alpha male mudah diidentifikasi didalam kelompoknya. Jantan dominan ini sangat berbeda dari jantan yang lain karena memiliki ciri-ciri tubuh yang berbeda serta tingkah laku yang sangat dominan terhadap yang lain sehingga sangat mempermudah dalam proses pengambilan data.

\section{Aktivitas grooming (menelisik) monyet hitam (Macaca nigra)}

Aktivitas grooming (menelisik) jantan dominan dapat dilihat pada gambar histogram (Gambar 1).
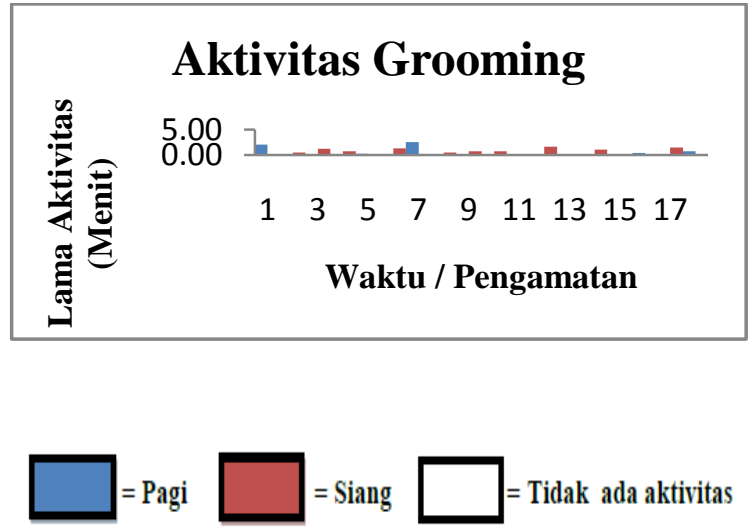

Gambar 1. Histogram Aktivitas grooming jantan dominan (alpha male)

Monyet Hitam (Macaca nigra) dapat menunjukkan perilaku grooming ketika dirinya merasa tidak nyaman atau ada gangguan pada daerah tubuhnya seperti kaki dan badan setelah mendapat parasit atau serangga lain yang menyerangnya. Grooming merupakan tindakan spontan yang akan dilakukan dengan interval waktu 2-3 menit, menggaruk, menangkap parasit yang menyerang dengan menggunakan kaki depan lalu mencium kemudian memakannya (Kinnaird, 1997 dalam Oscar, 2000; Korstjens et al., 2002). Grooming juga merupakan tingkah laku membersihkan badan temannya dengan meneliti bulu dan menggunakan jari-jari atau giginya (Pope, 1984). Tingkah laku merawat bulu disini diartikan sebagai suatu kegiatan mencari kutu atau parasit lain yang melekat pada bulu rambut Monyet 
Hitam (Macaca nigra) ini dapat dilakukan sendiri (autogrooming) ataupun berpasangan, kadang-kadang sampai beberapa ekor berderet-deret dan paling banyak dilakukanpada waktu kelompok sedang beristirahat (inactive). Grooming ada hubungannya dengan aktivitas seksual karena tidak jarang pada saat jantan dewasa di grooming, jantan tersebut bereaksi dan terjadi perkawinan (coitus) setelah kegiatan tersebut atau sebaliknya setelah melakukan perkawinan mereka sering melakukan grooming (Wilson, 1975; Henzi dan Barrett, 1999; Ventura et al., 2006; Schino dan Gabriele, 2007).

Data hasil penelitian menunjukkan bahwa aktifitas grooming Monyet Hitam (Macaca nigra) paling banyak pada siang hari (jam 10.00 keatas sedangkan pada pagi hari (08.00 - 10.00) aktivitas grooming tidak begitu banyak. Aktifitas grooming ini lebih banyak dilakukan jika kelompok sedang beristirahat. Hasil penelitian menunjukan bahwa aktivitas grooming jantan dominan (alpha male) selama 18 hari pengamatan paling lama terjadi pada siang hari. Hal ini disebabkan karena pada waktu menjelang siang hari monyet hitam (Macaca nigra) dalam keadaan beristirahat. Pada waktu terjadi autogrooming jantan menggaruk tubuhnya dan sekaligus mencari kutu. Sedangkan pada aktivitas grooming antara jantan dan betina biasanya mereka saling menggaruk tubuh dan jika terjadi coitus maka aktivitas terjadi sebelum dan sesudah coitus

Tingkah laku grooming biasanya dilakukan saat sedang beristirahat, dimana kelompok sedang dalam posisi inactive atau tidak melakukan apa-apa. Hasil pengamatan didapati bahwa tingkah laku grooming dari jantan dominan (alpha male) dibagi menjadi 3 bagian, yaitu tingkah laku grooming yang dilakukan sendiri (autogrooming), grooming yang dilakukan oleh betina dewasa lain dan grooming oleh dewasa yang lain. Tingkah laku grooming yang dilakukan alpha male/jantan dominan berupa membersihkan tubuh dari parasit yang menempel ditubuh (Wilson, 1975).

Aktifitas autogrooming pada waktu dari pagi sampai menjelang siang hari tidak begitu tinggi. Hal ini dikarenakan pada saat pagi merupakan waktu beraktifitas untuk mencari tempat yang memiliki banyak sumber makanannya. Frekuensi autogrooming jantan dewasa adalah lebih banyak dibandingkan dengan betina dewasa dan dewasa yang lain yang berkaitan dengan aktifitas seksual sangat sedikit bila dibandingkan dengan autogrooming. 
Aktifitas mencari makan (foraging) Monyet Hitam (Macaca nigra)

Aktivitas Mencari Makan (foraging) alpha male/jantan dominan dapat dilihat pada Gambar 2.

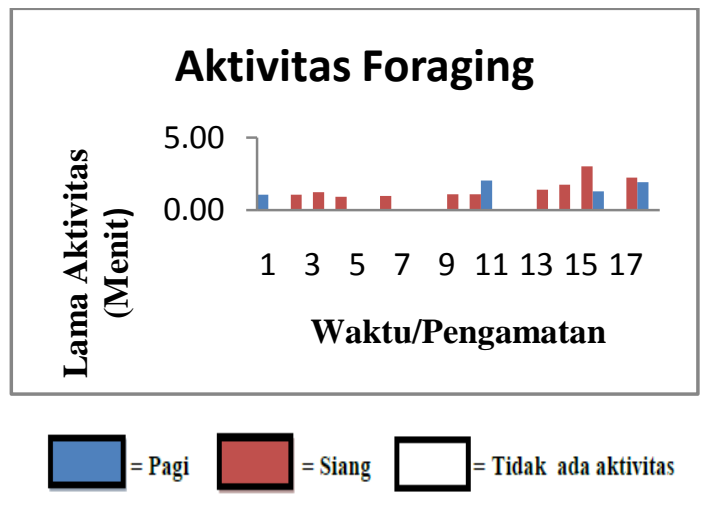

Gambar 2. Histogram aktifitas foraging dari alpha male/jantan dominan

Monyet Hitam (Macaca nigra) hidup dari memakan tumbuhan, sebagian besar makanannya terdiri dari buahbuahan, bunga, serangga, dan telur. Dari hasil pengamatan selama penelitian didapati bahwa aktifitas foraging mencari makan dilakukan antara Pukul 08:38 sampai Pukul 10-50. dan paling banyak dilakukan pada sekitar pukul 10:44 sampai pukul 10:48. Kebiasaan ini dilakukan karena dari pengamatan, pada jam seperti ini paling tinggi terjadi mencari makan (foraging) yang dilakukan oleh Monyet Hitam jantan dominan (Macaca nigra). Hasil penelitian Saroyo (2005), menunjukkan individu jantan dominan mempunyai akses yang lebih besar terhadap pakan dibandingkan dengan individu subordinate (bawahan).

Aktivitas ini berlangsung sekitar 0.9 - 3 menit selama waktu pengamatan. Pada waktu terjadi aktifitas foraging biasanya jantan dominan berjalan sambil mengawasi daerah yang dilaluinya sambil mencari makanan. Setelah menemukan makanan, maka makanan tersebut akan langsung dimakan. Selain itu biasanya makanan yang didapat tidak semua langsung ditelan, sebagian makanan dalam bentuk buah / bijian akan disimpan didaerah mulut (pipi) dan menjadi makanan cadangan.

\section{Tingkah laku agonistic (konflik)}

Aktivitas agonistic (konflik) alpha male/jantan dominan dapat dilihat pada Gambar 3.

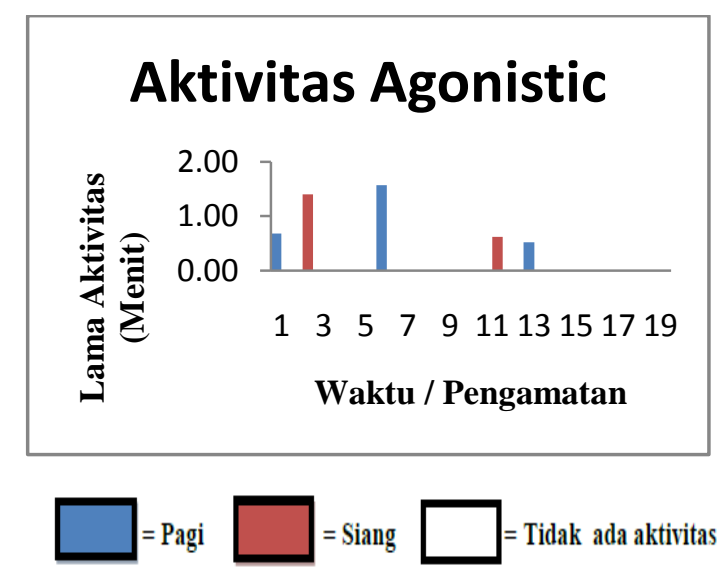

Gambar 3 Histogram aktifitas agonistic (konflik) dari alpha male/jantan dominan Macaca nigra 
Tingkah laku agonistic (konflik) umum dilakukan primata untuk mempertahankan wilayah, memperebutkan makanan serta untuk mempertahankan dominansi intergroup (Kinnard dan O’Brien, 1997 dalam Tasin, 2009) .

Hasil pengamatan tingkah laku agonistic diantara Monyet Hitam (Macaca nigra) hanya 3 kali terjadi selama waktu pengamatan terutama terjadi pada pagi hari. Hal ini mungkin disebabkan karena saat itu ketersediaan makanan cukup sehingga tingkah laku agonistic (konflik) belum muncul. Hal ini sejalan dengan pendapat Saroyo (2005), konflik karena kompetisi terhadap pakan terjadi jika kuantitas pakan yang tersedia dalam jumlah terbatas, atau jika sumber pakan yang tersedia sangat disukai monyet.

Data hasil pengamatan pada Gambar 3 menunjukkan bahwa untuk aktifitas agonistic (konflik) dari alpha male/jantan dominan adalah berlangsung antara 0.5 - 1.5 menit. Aktifitas konflik (agonistic) terjadi jika memperebutkan makanan namun dapat juga terjadi apabila bertemu dengan kelompok (intergroup) lain atau dapat juga terjadi pada sesama Jantan Dewasa yang ingin merebut kekuasaan jantan dominan atau betina favorit dari alpha male. Selama penelitian ini tidak dijumpai aktifitas agonistic intergroup karena yang diamati hanya jantan dominan dan tidak terjadi pertemuan dengan group lain.

\section{Aktifitas locomotion (bergerak)}

Aktivitas locomotion (bergerak) alpha male/jantan dominan dapat dilihat pada Gambar 4.

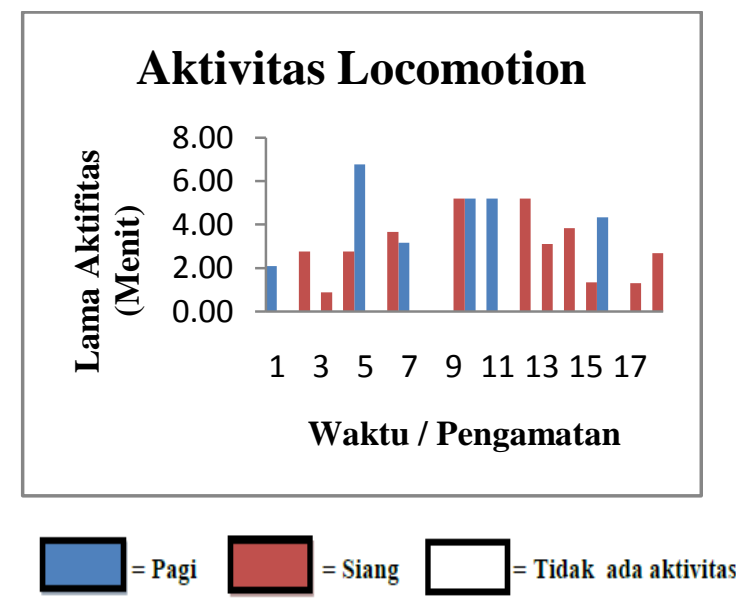

Gambar 4. Histogram aktifitas locomotion (bergerak) alpha male/jantan dominan Macaca nigra

Aktifitas locomotion (bergerak) yaitu pergerakan, termasuk berjalan, berlari, memanjat dan melompat. Aktivitas locomotion terutama dilakukan untuk mencari makanan. Aktifitas ini sangat dominan dalam spesies primata. Berdasarkan data pengamatan aktifitas ini dilakukan setelah aktifitas foraging termasuk makan dan inactive. Data aktifitas locomotion seperti yang diperlihatkan pada Gambar 4 adalah paling lama terjadi waktu menjelang siang 
hari yang menunjukkan bahwa Monyet Hitam/Macaca nigra (jantan dominan) memiliki mobilitas atau kemampuan jelajah yang tinggi Dari data interval aktifitas locomotion, rata-rata Monyet Hitam (Macaca nigra) melakukan aktifitas ini berkisar antara : pagi $2.08-6$ menit sedangkan siang hari antara 0,91 - 5,35 menit. Namun aktivitas locomotion paling banyak terjadi pada siang hari.

\section{Inactive (Tidak ada aktivitas)}

Tingkah laku inactive dari alpha male/jantan dominan dapat dilihat pada Gambar 5.
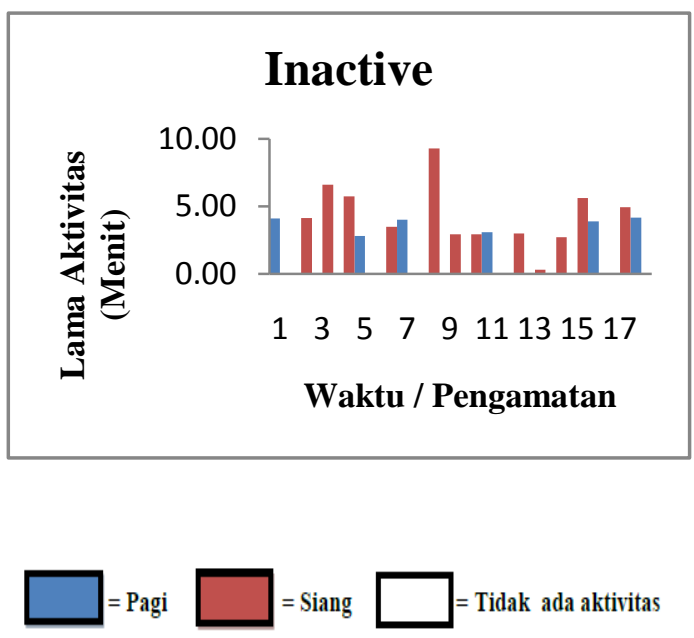

Gambar 5. Histogram inactive dari alpha male/jantan dominan

Tingkah laku inactive (istrirahat) biasanya duduk atau berbaring tetapi tidak termasuk dalam aktifitas sosial dan termasuk autogrooming sambil mengawasi daerah sekitarnya terhadap segala ancaman (Kinnard dan O’Brien, 1997 dalam Tasin, 2009). Setelah melakukan berbagai aktivitas seperti foraging dan locomotion, Monyet Hitam (Macaca nigra)/ jantan dominan akan memasuki waktu beristirahat. Tingkah laku atau kegiatan yang dilakukan monyet hitam (Macaca nigra) pada saat inactive ini biasanya duduk diam sambil mengawasi daerah sekitar (Gambar 5). Kadang kadang sambil menutup mata atau dalam gaya mengantuk akan tetapi sebenarnya mereka selalu dalam keadaan waspada sehingga kalau ada terjadi pergerakan tertentu atau kalau mendengar suara tertentu maka mereka akan sigap dalam mengantisipasi kemungkinan gangguan yang terjadi. Biasanya sang jantan dominan/alhpa male ini akan mengeluarkan suara nyaring (loud call) untuk memperingatkan pada kelompoknya kalau ada gangguan atau ancaman.

Hasil pengamatan menunjukkan bahwa aktivitas Inactive paling banyak dan paling lama terjadi dalam aktifitas harian dari alpha male/jantan dominan. Aktivitas inactive seperti pada Gambar 5 adalah berkisar $2.8-8.80$ menit. 


\section{Aktifitas kawin (coitus)}

Aktivitas kawin alpha male/jantan dominan dapat dilihat pada Gambar 6.

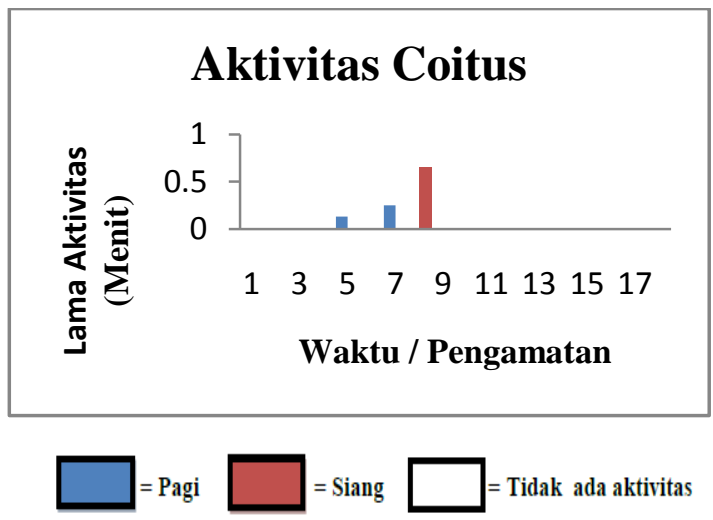

Gambar 6. Histogram Aktfitas coitus alpha male/jantan dominan

Tingkah laku kawin muncul karena adanya rangsangan dari dalam kemudian terjadi perkawinan jika ada rangsangan dari lawan jenisnya, dan dilakukan oleh satwa liar jantan dewasa dan betina dewasa (Alikodra, 1990). Tingkah laku kawin yang dilakukan oleh primata jantan dan betina dengan berbagai alasan antara lain untuk reproduksi, dan juga sebagai penampakan tingkah laku aviliatif /membersihkan diri (Siwi, 2001). Aktivitas kawin merupakan suatu rangkaian dalam melakukan kawin yang meliputi dari mencari pasangan sampai pada saat terjadi perkawinan. Aktivitas kawin biasanya diawali dengan adanya perilaku mendekati individu lain untuk kawin. Aktivitas kawin terjadi pada satwa dewasa baik jantan maupun betina. Collinge (1993) menyatakan bahwa dalam aktivitas kawin oleh jantan dipengaruhi oleh beberapa faktor untuk mendekati betina dan melakukan aktivitas kawin, yaitu : (1) koalisi antara jantan-jantan, (2) strategi alternatif yang dillakkukan oleh jantan-jantan sub-ordinan dan (3) pilihan betina untuk melakukan perkawinan.

Aktifitas Coitus dari Alpha Male/jantan tidak begitu menonjol pada alpha male/jantan dominan selama pengamatan. Hasil penelitian Saroyo (2005), menunjukkan bahwa frekuensi kawin tidak selalu berhubungan dengan peringkat jantan dalam kelompoknya. Takahashi (2004) dalam Saroyo (2005) menyatakan bahwa jantan dominan tidak selalu menunjukkan keberhasilan yang tinggi dalam reproduksi. Lebih lanjut dijelaskan bahwa sampai saat ini masih terjadi perdebatan tentang keterkaitan antara peringkat dominansi dengan keberhasilan reproduksi. Terdapat faktor monopili terhadap betina estrus, seekor jantan hanya dapat memonopoli satu betina pada suatu saat, sehingga jika ada lebih dari satu betina estrus, maka betina lain akan dimonopoli oleh jantan lain dibawahnya.

Hasil pengamatan hanya terdapat 3 kali aktifitas coitus dua kali pada pagi hari dan satu kali pada siang hari. Data hasil penelitian pada Gambar 6 menunjukkan bahwa waktu aktifitas coitus berlangsung 
selama $0,13-0,25$ menit pada pagi hari dan siang hari selama 0,65 menit.

Kurangnya aktifitas coitus dari alpha male disebabkan karena dia berasal dari kelompok lain (Rambo III). Jadi alpha male ini masih lebih suka menyendiri/menjauh dari anggota kelompok (Rambo I) dan masih sedang adaptasi dengan kelompoknya termasuk terhadap betina favorit. Alasan lainnya adalah karena Monyet Hitam mempunyai waktu tertentu dalam masa kesuburan dari betina dewasa dimana pada saat penelitian waktu/musim kawin Monyet Hitam (Macaca nigra) mungkin belum saatnya. Sehingga aktivitas coitus pada saat pengamatan ini di laksanakan adalah sedikit atau tidak significant. Data pengamatan juga menunjukkan bahwa durasi waktu coitus lebih pendek dari waktu coitus normal (2-3 menit). Penyebab dari durasi yang lebih singkat ini juga mungkin berkaitan dengan adanya perubahan daerah habitat dimana perubahan daerah teritorial/habitat akibat ulah manusia disekitarnya yang telah merubah ekosistim hutan serta peruntukan di sebagian wilayah dimana Monyet Hitam (Macaca nigra) berdomisili serta aktifitas sosial lain dari Monyet Hitam (Macaca nigra).

\section{KESIMPULAN}

Berdasarkan hasil dan pembahasan diatas maka dapat ditarik kesimpulan sebagai berikut:

(1). Aktifitas yang paling lama dilakukan alpha male/jantan dominan pada pagi hari adalah locomotion dan foraging dan agonistic. Sedangkan pada siang hari adalah foraging, locomotion, grooming, dan inactive.

(2). Aktifitas yang paling sedikit dilakukan baik pada pagi hari maupun siang hari adalah aktivitas kawin (coitus).

(3). Tingkah laku jantan dominan alpha male adalah berbeda dengan monyet hitam lainya dalam satu kelompok .

\section{DAFTAR PUSTAKA}

Alikodra, H.S., 1990. Pengelolaan Satwa Liar. Jilid III. PAU-Ilmu Hayat IPB Bogor

Collinge, N.G. 1993. Introduction To Primata Behavior, Kendal Huat Publishing Company, University of Alberta.

Dumanaw, D. 1997. Hubungan antara aktivitas Rusa Jawa (Cervus timorensis) dengan tipe vegetasi di Pulau Rinca Taman Nasional Komodo NTT. Jurusan Konservasi Sumber Daya Hutan Fakultas Kehutanan, IPB Bogor. 
Eimeri. S. dan I. Devore, 1984. Primata, Edisi Kedua. Tira Pustaka, Jakarta.

Henzi, S.P and L. Barrett. 1999. The value of grooming to female primates. Special Edition. Primate Socioecology 40(1): 47-59.

Korstjens, A.H., E.H.M. Sterck, and R. Noë. 2002. How adaptive or phylogenetically inert is primate social behaviour? A test with two sympatric colobines. Behaviour, Vol. 139 (2-3): 203-225.

MacKinnon, K. 1986, Alam Asli Indonesia, Yayasan Indonesia Hijau dan P.T. Gramedia Jakarta.

Mamangkei, F., 2002., Tingkah laku agonistik Macaca nigra kelompok Rambo 1 di cagar alam TangkokoDuasudara. Skripsi. Fakultas Peternakan Universitas Sam Ratulangi, Manado.

Manabung, A. 2000. Tingkah laku grooming monyet hitam (Macaca nigra) di cagar alam Tangkoko. Skripsi. Fakultas Peternakan Unsrat. Manado

Pope, G. 1984. Antropologi Biologi. CV. Rajawali. Jakarta.

Ventura, R., B. Majolo, N.F. Koyama, S. Hardie, and G. Schino. 2006. Reciprocation and interchange in wild Japanese macaques: grooming, cofeeding, and agonistic support. American Journal of Primatology, Volume 68:1138-1149

Saroyo, 2005. Karakteristik dominasi monyet hitam Sulawesi (Macaca nigra) di cagar alam Tangkoko
Batuangus. Sulawesi Utara. Disertasi. IPB Bogor.

Schino, G. 2007. Grooming and agonistic support: a meta-analysis of primate reciprocal altruism. Behavioral Ecology 18(1):115-120.

Siwi, J.W. 2001. Studi tingkah laku kawin (sexual behavior) Monyet Hitam (Macaca nigra) di Cagar Alam Tangkoko. Skripsi. Fakultas Peternakan Unsrat. Manado

Sugardjito, J., C.H. Southwick, J. Supriatna, A. Kohlhaas, S. Baker, J. Erwin, J. Froehlich, N. Lerche. 1989. Population survey of macaques in northern Sulawesi. American Journal of Primatology, 18(4): 285-301

Tasin, 2007. Tingkah laku agonistic Monyet Hitam Kelompok Rambo I di Cagar Alam Tangkoko Batuangus. Skripsi. Fakultas Peternakan Unsrat. Manado

Ventura, R., B. Majolo, N.F. Koyama, S. Hardie, and G. Schino. 2006. Reciprocation and interchange in wild Japanese macaques: grooming, cofeeding, and agonistic support. American Journal of Primatology, Volume 68:1138-1149

Whitten, A.J., M. Mustafa, and G.S. Handerson. 1987. Ekologi Sulawesi. Gadjah Mada University Press. Yogyakarta.

Wilson, E.O. 1975. Sociobiology: The New Synthesis. Harvard University Press: Cambridge. 